\title{
COMMENTARY \\ Oral Health and COVID-19: Increasing the Need for Prevention and Access
}

\author{
Zachary Brian, DMD, MHA ${ }^{1}$; Jane A. Weintraub, DDS, MPH ${ }^{2}$
}

\begin{abstract}
Accessible Version: www.cdc.gov/pcd/issues/2020/20_0266.htm
Suggested citation for this article: Brian Z, Weintraub JA. Oral Health and COVID-19: Increasing the Need for Prevention and Access. Prev Chronic Dis 2020;17:200266. DOI: https://doi.org/ 10.5888/pcd17.200266.
\end{abstract}

\section{PEER REVIEWED}

\section{Summary}

What is already known on this topic?

Oral health is an important component of health and overall well-being.

What is added by this report?

Nonemergency dental care has been curtailed during the coronavirus disease 2019 (COVID-19) pandemic. Reopening dental practices involves unique challenges and provides opportunities to increase focus on prevention and nonaerosol-generating procedures.

What are the implications for public health practice?

Vulnerable populations are at high risk for COVID-19 and oral and other chronic diseases, and they also have less access to health care services. Removing policy, regulatory, workforce, and reimbursement barriers and incentivizing prevention would increase access to oral health care and improve population health.

\section{Abstract}

Populations disproportionately affected by coronavirus disease 2019 (COVID-19) are also at higher risk for oral diseases and experience oral health and oral health care disparities at higher rates. COVID-19 has led to closure and reduced hours of dental practices except for emergency and urgent services, limiting routine care and prevention. Dental care includes aerosol-generating procedures that can increase viral transmission. The pandemic offers an opportunity for the dental profession to shift more toward nonaerosolizing, prevention-centric approaches to care and away from surgical interventions. Regulatory barrier changes to oral health care access during the pandemic could have a favorable impact if sustained into the future.

\section{Introduction}

On March 11, 2020, the World Health Organization declared the global spread of coronavirus disease 2019 (COVID-19) a pandemic (1). Severe acute respiratory syndrome coronavirus 2 (SARS$\mathrm{CoV}-2$ ) is a new virus with no vaccine or treatment, and the population currently has no immunity. The virus is primarily transmitted by direct or indirect personal contact through airborne respiratory droplets from an infected person (2).

On March 16, 2020, the American Dental Association (ADA), the nation's largest dental association, recommended that dental practices postpone elective dental procedures until April 6, 2020, and provide emergency-only dental services to help keep patients from burdening hospital emergency departments (3). Because of the rise of infections, this recommendation was updated on April 1, 2020, when the ADA advised offices to remain closed to all but urgent and emergency procedures until April 30 at the earliest. As a result, access to dental care substantially decreased. During the week of March 23, 2020, an ADA Health Policy Institute survey indicated that $76 \%$ of dental offices surveyed were closed but seeing emergency patients only, $19 \%$ were completely closed, and 5\% were open but seeing a lower volume of patients (4).

In addition to the lack of widespread COVID-19 testing, point-ofcare testing in dental offices also was not available. Because of the inability to test all patients and the fact that asymptomatic or presymptomatic patients could be infectious, ADA guidance shifted in mid-April 2020 as state and local government policies varied regarding criteria for reopening different types of services, including dental services (5). Questions remain about how soon patients will prioritize and resume nonemergency dental care amid other delayed health care services. The full extent of pandemicrelated financial strain and loss of dental insurance is not yet clear and will dramatically affect dental care utilization.

In this commentary, we explain why oral health care should be a public health priority in the response to the pandemic and discuss the aspects of dental care that make it challenging to accomplish this. We will also provide opportunities for improvement, such as focusing more on prevention and nonaerosolizing dental proced- 
ures and the means by which to increase access to affordable, more equitable care for vulnerable populations.

\section{Importance of Oral Health}

In 2000, the first and only Surgeon General's Report on Oral Health (the second is in progress) made clear that oral health is part of overall health and well-being (6). The mouth is indispensable to eating, speaking, smiling, and quality of life. The most prevalent oral conditions are dental caries and periodontal diseases, and they are largely preventable (7). Dental caries is the most common chronic childhood disease and continues into adulthood. Among US adults, 2011-2014 national data indicate that 32.7\% had untreated dental caries (8). Furthermore, according to weighted averages from 2009 through 2014, 42\% of adults aged 30 or older had periodontitis (9). Oral disease is unevenly distributed in the population by race and ethnicity (Table 1). The progression of oral disease can cause pain, infection, and sepsis, and treatment is expensive. In addition to primary prevention, in early stages the progression can be reversed or arrested with appropriate oral hygiene, fluoride exposure, dental sealants, changes in diet, and other measures.

\section{Populations With Oral Health and Chronic Disease Disparities: COVID-19 Puts Both at Increased Risk}

Populations at higher risk for many chronic diseases are similar to those at higher risk for developing oral diseases. Common risk factors include stress, poor diet, alcohol and tobacco use, substance misuse, behavioral health issues, domestic violence, and poverty. Many of these factors have been heightened during the pandemic. These and other social determinants of health lead to both exacerbation of chronic disease and poor oral health outcomes (13).

Populations vulnerable to COVID-19, including those in low socioeconomic groups, minority groups, older adults, low-literacy individuals, those in rural areas, and the uninsured are also at increased risk for oral disease and associated systemic health problems (14). Minority populations are especially at risk during the COVID-19 pandemic. The Centers for Disease Control and Prevention (CDC) notes that "non-Hispanic blacks, Hispanics, and American Indians and Alaska Natives generally have the poorest oral health of any racial and ethnic groups in the United States," (15) and these same populations have disproportionately higher incidence of COVID-19-related infection and death (16).

Among those hospitalized with COVID-19, diabetes and cardiovascular disease are 2 of the most prevalent underlying comor- bidities, according to the CDC (17). Periodontal disease is associated with diabetes and cardiovascular disease, although causality is difficult to ascertain because of confounding evidence, and few randomized trials or longitudinal studies have been conducted on the effects of treatment $(18,19)$.

Researchers note, "The COVID-19 pandemic has alarming implications for individual and collective health and emotional and social functioning" and that "health care providers have an important role in monitoring psychosocial needs and delivering psychosocial support to their patients" (20). Research suggests a strong association between oral health conditions like erosion, caries, and periodontal disease and mood conditions like stress, anxiety, depression, and loneliness (21). There are other potential connections downstream between COVID-19 and oral health. With the COVID-19 pandemic's impact on mental health, pandemic-related increases in oral health risk factors, and anticipated declines in per capita dental visits, increasing integrated practice and referrals between dental providers and behavioral health providers will be prudent. Similarly, increased efforts to more effectively integrate dental programs focused on prevention, screening, and risk assessment within primary care, obstetrics and gynecology, and pediatric offices should be pursued to expand access to oral health services for vulnerable populations (22).

\section{COVID-19 and Oral Health Disparities in Access to Care}

Access to oral health care is especially limited for populations at high risk for COVID-19. Patients with symptoms of COVID-19 are advised "to avoid nonemergent dental care" (23). Providers are advised, "if possible, [to] delay dental care until the patient has recovered" (23).

More than 49 million US residents live in areas designated by the Health Resources and Services Administration as Dental Health Professional Shortage Areas (24). This shortage has been compounded by the COVID-19 pandemic, which has resulted in limited preventive dental services in the interest of public health safety. Emergency departments, a less-than-ideal but common treatment destination for those facing oral health care access disparities, have also seen a significant drop in visits for health problems unrelated to COVID-19 (25). School-based oral health programs, such as effective dental sealant programs to prevent dental caries - the only source of preventive oral health care for many children in vulnerable populations - have similarly been suspended because of government-mandated school closures (26). Nationally, children in low-income families and at higher risk of caries are less likely to receive sealants than children in higherincome families, at $39 \%$ and $46 \%$, respectively (27).

The opinions expressed by authors contributing to this journal do not necessarily reflect the opinions of the U.S. Department of Health and Human Services, the Public Health Service, the Centers for Disease Control and Prevention, or the authors' affiliated institutions. 
Access disparities are particularly acute for poor and minority populations. Researchers note that "poor and minority children are substantially less likely to have access to oral health care than their nonpoor and nonminority peers" (14). These populations are also more likely to lack dental insurance. A 2020 report notes, "The oral health care safety net is expected to cover ... one-third of the US population, notably those who are low-income, uninsured, and/ or members of racial/ethnic minority, immigrant, rural, and other underserved groups" (28). Many of these populations, which often rely on Medicaid dental benefits, have seen their access restricted or eliminated by reductions in this vital coverage. In 2020 it was reported that "in response to fiscal challenges, many states have reduced or eliminated Medicaid dental coverage over the past decade, with a concurrent $10 \%$ decline in oral health care utilization among low-income adults" (28). Among those in at-risk populations who do have dental benefits under Medicaid, the same report notes there is often "difficulty finding Medicaid-contracted dental providers, because only $20 \%$ of dentists nationwide accept Medicaid" (28). We can reasonably anticipate a worsening of these trends as the COVID-19 pandemic takes a large proportion of state budgets.

\section{COVID-19 and Dental Care: Aerosol- Generating Procedures Create Risk}

Dental professionals have been practicing increased infection control and taking universal precautions since the 1980s HIV epidemic (29). Nevertheless, oral health professionals are among those occupations at the highest risk for COVID-19, as reported by The New York Times (30). Dental care personnel face challenges because of their proximity to infected patients. These patients' mouths are open and unmasked during treatment, significantly increasing the potential for direct and indirect exposure to infectious materials. The Occupational Safety and Health Administration designates the performance of aerosol-generating procedures on known or suspected COVID-19 patients as "very high risk" (31). Shortages of personal protective equipment (PPE) and the use of instruments and equipment that generate aerosols containing oral and respiratory fluids only compound the risk (23). Two of the highest aerosol-creating procedures involve inventions that have been considered major advances in dental practice, because they are faster and less painful for the patient: the high-speed handpiece with its water spray coolant and the ultrasonic scaler used by hygienists to remove hard deposits on teeth (32). These dental procedures have become problematic during the pandemic, providing an opportunity to shift to nonaerosolizing procedures and a greater focus on prevention $(23,33)$.

\section{Going Forward: Opportunities}

\section{Focus on prevention and promote nonaerosol- generating dental procedures}

Prevention is a cornerstone of public health. The COVID-19 pandemic presents an opportunity for the dental profession to shift from an approach focused on surgical intervention to one emphasizing prevention. Embracing nonsurgical, nonaerosolizing caries prevention and management will be critical in this endeavor. The profession has always supported community water fluoridation, and dental hygienists are considered prevention experts $(34,35)$. However, the dental compensation model is based on providing expensive, restorative procedures that are financially out of reach for many people.

Guidelines have been developed to shift the dental care paradigm to a more preventive focus (36-40). Strategies include reduction in common risk factors such as tobacco and alcohol use, promotion of a healthy diet low in sugars, community water fluoridation, topical fluorides, and promotion of oral health in community settings. These oral health messages and interventions should be integrated into medical sites such as primary care and pediatric offices. Prevention and nonsurgical caries management include many options. Evidence-based materials include dental resin sealants, glass ionomers as sealants or as part of atraumatic restorative treatment performed with hand instruments, silver diamine fluoride, sodium fluoride varnish, and other self-applied and professionally applied topical fluorides (40-42). These materials can be applied without generating aerosols, reducing the risk of viral transmission. These methods present a major opportunity to expand access to preventive and restorative care for vulnerable populations, particularly when combined with policy changes increasing hygienists' scope of practice, sustainable payment reform, and changes in the education of oral health professionals.

Providers and payers together have a responsibility to shift toward preventive care, particularly as COVID-19 threatens to increase disparities in oral health care access for the United States' most vulnerable populations. Before the pandemic, Birch et al noted that a review of provider and payer practices made clear that "further work was required on both the provider and payer side to ensure that evidence-based prevention was both implemented properly but also reimbursed sufficiently" (43). As health care compensation moves toward value-based care and a focus on health outcomes, prevention and maintaining oral health and sound tooth structure will shift reimbursement away from the current expensive model of reimbursement for restoration of tooth structure and

The opinions expressed by authors contributing to this journal do not necessarily reflect the opinions of the U.S. Department of Health and Human Services, the Public Health Service, the Centers for Disease Control and Prevention, or the authors' affiliated institutions. 
function (44). In particular, reimbursement policies, which traditionally have incentivized surgical, high-end restorative procedures like crowns and multisurface fillings, must be revisited to prioritize preventive and nonsurgical, nonaerosolizing treatments and make them more financially sustainable.

\section{Improve communication}

Communications concerning patient and provider safety are critical (45). Surveillance and monitoring are needed to confirm whether transmission of COVID-19 occurs in the dental office. According to CDC (27), "There are currently no data available to assess the risk of SARS-CoV-2 transmission during dental practice." The availability of PPE for dental care should be monitored, and the effectiveness of various types of PPE should be determined. Many oral health care providers are anxious about returning to work, and many patients may be hesitant to enter a dental office. Communication and clarity are critical, especially with low-literacy populations. Messaging should include the importance of maintaining good oral health and its role in overall health.

\section{Protect and enhance Medicaid reimbursement}

Dental coverage under Medicaid is mandated for children, but state Medicaid programs' approaches to oral health services for adults vary significantly, especially in terms of the comprehensive nature of such services (Figure). Only 19 states have "extensive" Medicaid dental benefits for adults (46). Among US adults aged 19 to 64 , only $7.4 \%$ have Medicaid dental benefits and, alarmingly, 33.6\% have no dental insurance benefits (47). The fiscal solvency of dental safety-net clinics will thus remain critical to serving at-risk populations during and after the pandemic. These sites will be needed more than ever, as delayed and postponed treatment increases need for more extensive and urgent care.

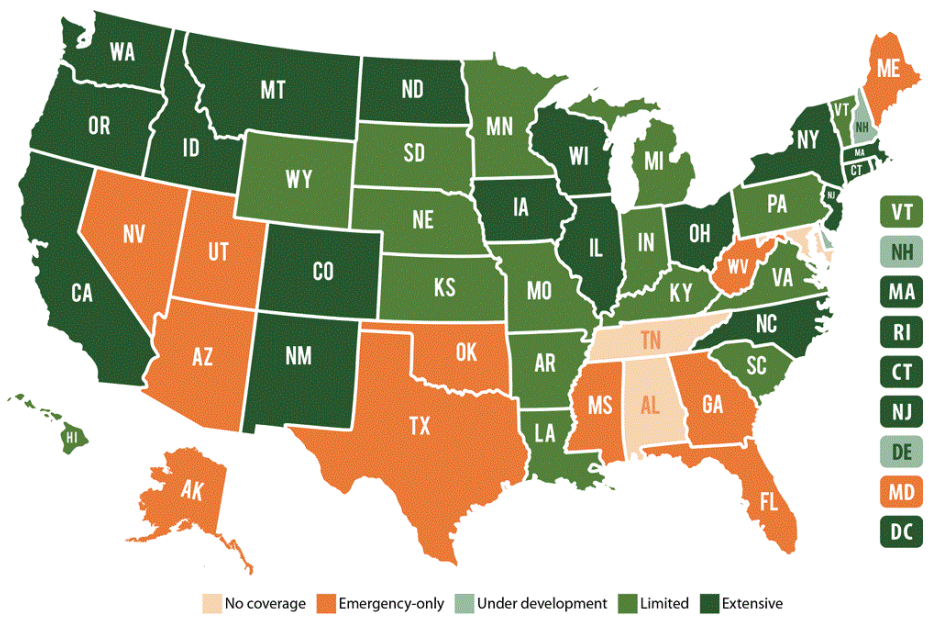

Figure. Extent of Medicaid adult dental benefits, by state. Source: Center for Health Care Strategies (46).

It is widely documented that during economic downturns, Medicaid enrollment increases (48). With unemployment increasing at an unprecedented rate, we can reasonably anticipate the same effect in this pandemic. During times of state budget cuts, dental Medicaid coverage is often at risk (49). In the immediate aftermath of the Great Recession during state fiscal years 2010 through 2012, 19 states reported restrictions in Medicaid adult dental benefits (50). Amidst the pandemic, many states have modified public payment policies to meet the demand of their most vulnerable residents, and it will be important that advocacy efforts secure continuity of these provisional changes. However, given current circumstances, it is imperative that policy makers consider expanding adult dental benefits under Medicaid rather than reducing them. Access disparities will likely increase without expansion of dental benefits under Medicaid.

\section{Ease dental workforce restrictions}

Guidance for dental practice during COVID-19 continues to evolve, and regulations vary by state (51). As dental care resumes, it is critical that workforce policies and licensure scope are evaluated to address workforce utilization bottlenecks to respond to communities' needs more effectively and efficiently.

As of 2019, 11 states did not allow for some form of direct access to preventive oral health services by a dental team member outside of the dentist's supervision (52). In these states, a dentist must perform an examination before delivery of preventive care by a hygienist. Easing scope of practice and workforce restrictions would increase access to care. Increasing opportunities for dental

\footnotetext{
The opinions expressed by authors contributing to this journal do not necessarily reflect the opinions of the U.S. Department of Health and Human Services, the Public Health Service, the Centers for Disease Control and Prevention, or the authors' affiliated institutions.
} 
team members like dental therapists, community dental health coordinators, and expanded function dental assistants - all currently in limited supply and restricted by dental practice acts in many states - would help bring needed, more affordable services to underserved communities.

\section{Advance teledentistry to address access gaps}

The COVID-19 pandemic has thrust alternative modalities such as teledentistry to the forefront of policy considerations (53). Teledentistry supports the delivery of oral health services through electronic communication means, connecting providers and patients without usual time and space constraints. Teledentistry's unique ability to connect disadvantaged, primarily rural communities and the homebound with dental providers (54) makes this method particularly well-suited to address lack of access during and after the pandemic.

Teledentistry can be used for education, consultation, and triage, allowing providers to advise patients whether their dental concerns constitute a need for urgent or emergency care, whether a condition could be temporarily alleviated at home, or whether treatment could be postponed. When many dental offices are closed and people are largely staying at home, communication and information via teledentistry can help lessen the burden of people seeking dental care at overwhelmed emergency departments and urgent dental care settings. In more usual circumstances, teledentistry can also be used to facilitate access to preventive services and oral health education when members of the dental team can provide such services in community settings, such as schools, without onsite dentist supervision.

Before COVID-19, many states inhibited use of teledentistry through legislative barriers and limited public and private insurance reimbursement. Compared with dentistry, many medical and behavioral health providers have less restrictive regulations and insurance reimbursement policies concerning telehealth. A Washington Post report (55) was clear: "Telemedicine was largely ready for the influx." Teledentistry, on the other hand, was forced to play catch-up (56). Emergency reimbursement changes prompted by COVID-19 have brought relief, but post-pandemic, we recommend that legislators, regulatory authorities, and third-party payers consider making permanent the temporary modifications to teledentistry policies to support increased access.

\section{Implications for Public Health Practice: Dental Public Health's Roles}

Health inequities are avoidable and unjust. Although SARS-Cov-2 has infected people worldwide, it has disproportionately affected those who are most disadvantaged. In the United States, people without good access to health care, healthy food, and a safe environment; with underlying health conditions; who live in crowded conditions; or who have become unemployed and homeless are especially vulnerable and at increased exposure to the virus. It is time to recognize the social determinants of health and rectify unjust conditions, systemic inequality, and racism.

Oral health disparities and inequities are part of the larger, cultural picture. There has been a tendency to blame the victim. Mary Otto, health journalist and author of the groundbreaking book Teeth (57), stated, "We see tooth decay through a moral lens, almost. We judge people who have oral disease as moral failures, rather than people who are suffering from a disease" (58).

It is perhaps not hyperbole to describe pandemic-related circumstances as creating a "perfect storm" in oral health care in the United States. Risk factors are elevated, access for the most vulnerable is limited, safety concerns are heightened, and the economy presents substantial challenges for patients and providers alike. The effects of COVID-19 are particularly acute for vulnerable populations, and the crisis has made evident the challenges and opportunities for oral health care in the United States. In such a time, oral health care providers and advocates must clearly communicate the importance of oral health to overall health, indicate the steps being taken to ensure patient and provider safety, and promote prevention and nonaerosolizing procedures (Table 2). Oral health should be included in policy considerations, continued research, monitoring, surveillance, and other aspects of health. Advocacy is crucial to make permanent the temporary regulatory changes being implemented to address the immediate crisis, ensure access to oral health care, address disparities and inequities, and improve population health.

\section{Acknowledgments}

The authors received no financial support for this work. The findings and conclusions in this report are those of the authors and do not necessarily represent the official position of the Centers for Disease Control and Prevention. No borrowed material, copyrighted surveys, instruments, or tools were used for this article.

\section{Author Information}

Corresponding Author: Zachary Brian, DMD, MHA, Director, North Carolina Oral Health Collaborative, Foundation for Health Leadership and Innovation, 2401 Weston Parkway, Suite 203, Cary, NC 27513. Telephone: 231-340-1732. Email: zachary.brian@foundationhli.org.

The opinions expressed by authors contributing to this journal do not necessarily reflect the opinions of the U.S. Department of Health and Human Services, the Public Health Service, the Centers for Disease Control and Prevention, or the authors' affiliated institutions. 
Author Affiliations: ${ }^{1}$ North Carolina Oral Health Collaborative, Foundation for Health Leadership and Innovation, Cary, North Carolina. ${ }^{2}$ University of North Carolina at Chapel Hill Adams School of Dentistry and Gillings School of Global Public Health, Chapel Hill, North Carolina.

\section{References}

1. World Health Organization. Coronavirus disease (COVID-19) pandemic. https://www.who.int/emergencies/diseases/novelc $\quad \begin{array}{lllllllllllllllllllll} & \mathrm{r} & \mathrm{o} & \mathrm{n} & \mathrm{a} & \mathrm{v} & \mathrm{i} & \mathrm{r} & \mathrm{u} & \mathrm{s} & - & 2 & 0 & 1 & 9 & \text { ? } & \mathrm{g} & \mathrm{c} & \mathrm{l} & \mathrm{i} & \mathrm{d}=\end{array}$ EAIaIQobChMImpGHv7Do6QIVTLLICh2QdgaOEAAYASA AEgKT-PD_BwE. Accessed May 28, 2020.

2. Bahl P, Doolan C, de Silva C, Chughtai AA, Bourouiba L, MacIntyre CR. Airborne or droplet precautions for health workers treating COVID-19? J Infect Dis 2020;jiaa189.

3. American Dental Association. ADA recommending dentists postpone elective procedures. https://www.ada.org/en/ publications/ada-news/2020-archive/march/adarecommending-dentists-postpone-elective-procedures. Accessed May 28, 2020.

4. American Dental Association. HPI poll examines impact of COVID-19 on dental practices. https://stage.ada.org/en/ publications/ada-news/2020-archive/april/hpi-poll-examinesi m pact - of - covid-19-on-dental-practices? $\mathrm{ga}=2.60007597 .1221223386 .1587062986-$ 9041569.1523984324. Accessed July 1, 2020.

5. American Dental Association. As some states consider reopening, ADA offers PPE guidance to dentists. https:// www.ada.org/en/press-room/news-releases/2020-archives/ april/postponement-statement. Accessed May 28, 2020.

6. US Department of Health and Human Services. Oral health in America: a report of the Surgeon General. https:// www.nidcr.nih.gov/sites/default/files/2017-10/ hck1 ocv.\%40www.surgeon.fullrpt.pdf. Accessed June 30, 2020.

7. Jepsen S, Blanco J, Buchalla W, Carvalho JC, Dietrich T, Dörfer $\mathrm{C}$, et al. Prevention and control of dental caries and periodontal diseases at individual and population level: consensus report of group 3 of joint EFP/ORCA workshop on the boundaries between caries and periodontal diseases. J Clin Periodontol 2017;44(Suppl 18):S85-93.

8. Kaye EA, Sohn W, Garcia RI. The Healthy Eating Index and coronal dental caries in US adults: National Health and Nutrition Examination Survey 2011-2014. J Am Dent Assoc 2020;151(2):78-86.
9. Eke PI, Thornton-Evans GO, Wei L, Borgnakke WS, Dye BA, Genco RJ. Periodontitis in US Adults: National Health and Nutrition Examination Survey 2009-2014. J Am Dent Assoc 2018;149(7):576-588.e6.

10. Centers for Disease Control and Prevention. COVIDView: a weekly surveillance summary of US COVID-19 activity. https://www.cdc.gov/coronavirus/2019-ncov/covid-data/ covidview/index.html. Accessed June 28, 2020.

11. Centers for Disease Control and Prevention. Oral health surveillance report 2019. Table 26: percentage of dentate adults aged 20-64 with untreated tooth decay in permanent teeth. https://www.cdc.gov/oralhealth/publications/ OHSR2019-table-26.html. Accessed June 4, 2020.

12. Centers for Disease Control and Prevention. Health, United States. Spotlight: racial and ethnic disparities in heart disease; 2019 . https://www.cdc.gov/nchs/hus/spotlight/ HeartDiseaseSpotlight_2019_0404.pdf. Accessed June 4, 2020.

13. Watt RG, Sheiham A. Integrating the common risk factor approach into a social determinants framework. Community Dent Oral Epidemiol 2012;40(4):289-96.

14. The National Academies, Institute of Medicine and National Research Council, Committee on Oral Health Access to Services. Improving access to oral health care for vulnerable and underserved populations. https://www.hrsa.gov/sites/ default/files/publichealth/clinical/oralhealth/ improvingaccess.pdf. Accessed May 28, 2020.

15. Centers for Disease Control and Prevention. Disparities in oral health. https://www.cdc.gov/oralhealth/oral_health_disparities/ index.htm. Accessed May 28, 2020.

16. Centers for Disease Control and Prevention. COVID-19 in racial and ethnic minority groups. https://www.cdc.gov/ coronavirus/2019-ncov/need-extra-precautions/racial-ethnicminorities.html. Accessed July 1, 2020.

17. Centers for Disease Control and Prevention. People of any age with underlying medical conditions. https://www.cdc.gov/ coronavirus/2019-ncov/need-extra-precautions/people-with$\mathrm{medic}$ a 1 - c o n d i t i o n s h t m l ? C D C A A refVal $=$ https $\% 3 \mathrm{~A} \% 2 \mathrm{~F} \% 2 \mathrm{Fwww} . c d c . g o v \% 2 \mathrm{Fcoronavirus} \% 2 \overline{\mathrm{F}}$ 2019-ncov\%2Fneed-extra-precautions \%2Fgroups-at-higherrisk.html. Accessed July 1, 2020.

18. Winning L, Linden GJ. Periodontitis and systemic disease: association or causality? Curr Oral Health Rep 2017;4(1):1-7.

19. Liu W, Cao Y, Dong L, Zhu Y, Wu Y, Lv Z, et al. Periodontal therapy for primary or secondary prevention of cardiovascular disease in people with periodontitis. Cochrane Database Syst Rev 2019;12(12):CD009197.

20. Pfefferbaum B, North CS. Mental health and the COVID-19 pandemic. N Engl J Med 2020;NEJMp2008017.

\footnotetext{
The opinions expressed by authors contributing to this journal do not necessarily reflect the opinions of the U.S. Department of Health and Human Services, the Public Health Service, the Centers for Disease Control and Prevention, or the authors' affiliated institutions.
} 
21. Kisely S.No mental health without oral health. Can J Psychiatry 2016;61(5):277-82.

22. Atchison KA, Rozier RG, Weintraub JA. Integration of oral health and primary care: communication, coordination, and referral. Discussion paper. Washington (DC): National Academy of Medicine; 2018. https://nam.edu/integration-oforal-health-and-primary-care-communication-coordinationand-referral/. Accessed July 26, 2020.

23. Centers for Disease Control and Prevention. Guidance for dental settings. https://www.cdc.gov/coronavirus/2019-ncov/ hcp/dental-settings.html. Accessed May 28, 2020.

24. Bersell $\mathrm{CH}$. Access to oral health care: a national crisis and call to reform. J Dent Hyg 2017;91(1):6-14.

25. Wong LE, Hawkins JE, Langness S, Murrell KL, Iris P, Sammann A. Where are all the patients? Addressing COVID19 fear to encourage sick patients to seek emergency care. $\mathrm{N}$ Engl J Med Catalyst 2020. https://catalyst.nejm.org/doi/pdf/ 10.1056/CAT.20.0231

26. Centers for Disease Control and Prevention. School dentalsealant programs could prevent most cavities, lower treatment costs in vulnerable children. https://www.cdc.gov/media/ releases/2016/p1018-dental-sealants.html. Accessed July 20, 2020.

27. Griffin SO, Wei L, Gooch BF, Weno K, Espinoza L. Vital signs: dental sealant use and untreated tooth decay among U.S. school-aged children. MMWR Morb Mortal Wkly Rep 2016; 65(41):1141-5.

28. Northridge ME, Kumar A, Kaur R. Disparities in access to oral health care. Annu Rev Public Health 2020;41(1):513-35.

29. Kohn WG, Collins AS, Cleveland JL, Harte JA, Eklund KJ, Malvitz DM; Centers for Disease Control and Prevention (CDC). Guidelines for infection control in dental health-care settings — 2003. MMWR Recomm Rep 2003;52(RR-17,RR17):1-61.

30. Gamio L. The workers who face the greatest coronavirus risk. The New York Times. Mar 15,2020. https:// www.nytimes.com/interactive/2020/03/15/business/economy/ coronavirus-worker-risk.html. Accessed July 16, 2020.

31. Occupational Safety and Health Administration. Dentistry workers and employers. https://www.osha.gov/SLTC/covid19/dentistry.html. Accessed May 28, 2020.

32. Harrel SK, Molinari J. Aerosols and splatter in dentistry: a brief review of the literature and infection control implications. J Am Dent Assoc 2004;135(4):429-37.

33. Ge ZY, Yang LM, Xia JJ, Fu XH, Zhang YZ. Possible aerosol transmission of COVID-19 and special precautions in dentistry. J Zhejiang Univ Sci B 2020;21(5):361-8.
34. American Dental Association. ADA fluoridation policy. http:// www.ada.org/en/public-programs/advocating-for-the-public/ fluoride-and-fluoridation/ada-fluoridation-policy. Accessed July 1, 2020.

35. American Dental Hygienists' Association. Standards for clinical dental hygiene practice. https://www.adha.org/ resources-docs/2016-Revised-Standarrds-for-ClinicalHygiene-Practice.pdf. Accessed July 1, 2020.

36. Scottish Intercollegiate Guidelines Network. Dental interventions to prevent caries in children. https:// www.sign.ac.uk/assets/sign138.pdf. Accessed June 30, 2020.

37. Pitts NB, Zero DT. White paper on dental caries prevention and management. A summary of the current evidence and key issues in controlling this preventable disease. FDI World Dental Federation. http://www.fdiworlddental.org/sites/default/ files/media/documents/2016-fdi_cpp-white_paper.pdf. Accessed July 16, 2020.

38. Public Health England. Delivering better oral health: an evidence-based toolkit for prevention. Third edition. https:// www.gov.uk/government/uploads/system/uploads/attachment data/file/601832/delivering_better_oral_health.pdf. Accessed June 30, 2020.

39. Slayton RL, Urquhart O, Araujo MWB, Fontana M, GuzmánArmstrong S, Nascimento MM, et al. Evidence-based clinical practice guideline on nonrestorative treatments for carious lesions: a report from the American Dental Association. J Am Dent Assoc 2018;149(10):837-849.e19.

40. Urquhart O, Tampi MP, Pilcher L, Slayton RL, Araujo MWB, Fontana $\mathrm{M}$, et al. Nonrestorative treatments for caries: systematic review and network meta-analysis. J Dent Res 2019;98(1):14-26.

41. Al-Halabi M, Salami A, Alnuaimi E, Kowash M, Hussein I. Assessment of paediatric dental guidelines and caries management alternatives in the post COVID-19 period. A critical review and clinical recommendations. Eur Arch Paediatr Dent 2020.

42. Cianetti S, Pagano S, Nardone M, Lombardo G. Model for taking care of patients with early childhood caries during the SARS-Cov-2 pandemic. Int J Environ Res Public Health 2020; 17(11):3751.

43. Birch S, Bridgman C, Brocklehurst P, Ellwood R, Gomez J, Helgeson $\mathrm{M}$, et al. Prevention in practice - a summary. BMC Oral Health 2015;15(S1,Suppl 1):S12.

44. Pitts NB, Zero DT, Marsh PD, Ekstrand K, Weintraub JA, Ramos-Gomez F, et al. Dental caries. Nat Rev Dis Primers 2017;3(1):17030.

The opinions expressed by authors contributing to this journal do not necessarily reflect the opinions of the U.S. Department of Health and Human Services, the Public Health Service, the Centers for Disease Control and Prevention, or the authors' affiliated institutions. 
45. World Health Organization. Risk communication and community engagement readiness and response to coronavirus disease (COVID-19): interim guidance. https://www.who.int/ publications/i/item/risk-communication-and-communityengagement-readiness-and-initial-response-for-novelcoronaviruses-(-ncov). Accessed July 1, 2020.

46. Center for Health Care Strategies. Medicaid adult dental benefits: an overview. https://www.chcs.org/media/Adult-OralHealth-Fact-Sheet_091519.pdf. Accessed May 28, 2020.

47. American Dental Association. Dental benefits and Medicaid. https://www.ada.org/en/science-research/health-policyinstitute/dental-statistics/dental-benefits-and-medicaid. Accessed May 28, 2020.

48. Benitez J, Perez V, Seiber E. Medicaid access during economic distress: lessons learned from the great recession. Med Care Res Rev 2020;1077558720909237.

49. Decker SL, Lipton BJ. Do Medicaid benefit expansions have teeth? The effect of Medicaid adult dental coverage on the use of dental services and oral health. J Health Econ 2015; 44:212-25.

50. Snyder L, Rudowitz R. Trends in state Medicaid programs: looking back and looking ahead. Kaiser Family Foundation; 2016. https://www.kff.org/medicaid/issue-brief/trends-in-statemedicaid-programs-looking-back-and-looking-ahead/view/ print/. Accessed July 16, 2020.

51. ADA Center for Professional Success. COVID-19 state mandates and recommendations. https://success.ada.org/en/ practice-management/patients/covid-19-state-mandates-andrecommendations. Accessed July 1, 2020.

52. Oral Health Workforce Research Center. Variation in dental hygiene scope of practice by state. http:// www.oralhealthworkforce.org/wp-content/uploads/2019/01/ Single-Page-Layout-Final-2019.pdf. Accessed May 28, 2020.

53. DentaQuest. COVID-19 puts teledentistry in the spotlight; 2020. https://whatsnew.dentaquest.com/covid-19-putsteledentistry-in-the-spotlight/. Accessed July 8, 2020.

54. Jampani ND, Nutalapati R, Dontula BS, Boyapati R. Applications of teledentistry: A literature review and update. J Int Soc Prev Community Dent 2011;1(2):37-44.

55. Kritz F. Telemedicine keeps doctors and patients connected at a safe remove. The Washington Post. May 16, 2020. https:// www.washingtonpost.com/health/telemedicine-keeps-doctorsand-patients-connected-at-a-safe-remove/2020/05/14/ 5f1 fa262-742b-11ea-ae50-7148009252e3_story.html. Accessed July 16, 2020.

56. Hartwell C; California Dental Association. Teledentistry beyond COVID-19: applications for private practice; 2020. https://www.cda.org/Home/News-and-Events/Newsroom/ Article-Details/teledentistry-beyond-covid-19-applications-forprivate-practice. Accessed July 1, 2020.
57. Otto M. Teeth: the story of beauty, inequality, and the struggle for oral health in America. 1st edition. New York (NY): The New Press; 2017.

58. Beck J. Why dentistry is separate from medicine: the divide sometimes has devastating consequences. The Atlantic. March 9, 2017. https://www.theatlantic.com/health/archive/2017/03/ why-dentistry-is-separated-from-medicine/518979/. Accessed July 16,2020

\footnotetext{
The opinions expressed by authors contributing to this journal do not necessarily reflect the opinions of the U.S. Department of Health and Human Services, the Public Health Service, the Centers for Disease Control and Prevention, or the authors' affiliated institutions.
} 


\section{Tables}

Table 1. Percentage of COVID-19 Hospitalized Cases in COVID-NET Catchment Areas and Prevalence of Dental and Other Chronic Conditions in the United States, by Race/Ethnicity, 2020

\begin{tabular}{|c|c|c|c|c|c|c|}
\hline Characteristic & $\begin{array}{l}\% \text { of COVID-19 } \\
\text { Hospitalized Cases }\end{array}$ & $\begin{array}{l}\text { COVID-NET Catchment } \\
\text { Area for Comparison }\end{array}$ & $\begin{array}{l}\text { \% of Periodontitis } \\
\text { (Gum Disease) }\end{array}$ & $\begin{array}{l}\text { \% of Untreated } \\
\text { Dental Caries } \\
\text { (Tooth Decay) }\end{array}$ & $\begin{array}{l}\text { \% With Diabetes } \\
\text { (Physician- } \\
\text { Diagnosed and } \\
\text { Undiagnosed) }\end{array}$ & $\begin{array}{l}\% \text { of Self- } \\
\text { Reported } \\
\text { Heart Disease }\end{array}$ \\
\hline Population & $\begin{array}{l}\text { COVID-NET, } 14 \\
\text { jurisdictions }\end{array}$ & $\begin{array}{l}\text { COVID-NET, } 14 \\
\text { jurisdictions }\end{array}$ & $\begin{array}{l}\text { US dentate adults } \\
\text { aged } \geq 30 \text { y }\end{array}$ & $\begin{array}{l}\text { US dentate adults } \\
\text { aged } 20-64 \text { y }\end{array}$ & US adults aged $\geq 20 y$ & $\begin{array}{l}\text { US adults aged } \\
\geq 18 \mathrm{y}\end{array}$ \\
\hline Period & As of June 20,2020 & As of June 20, 2020 & 2009-2014 & 2011-2016 & 2015-2016 & 2017 \\
\hline Source & CDC (10) & CDC (10) & NCHS, NHANES (9) & NCHS, NHANES (11) & NCHS, NHANES (12) & $\begin{array}{l}\text { NCHS, NHIS } \\
(12)\end{array}$ \\
\hline Non-Hispanic White & 32.8 & 58.8 & 37.0 & 22.2 & 13.0 & 11.5 \\
\hline Non-Hispanic Black & 32.6 & 17.7 & 56.6 & 40.2 & 19.6 & 9.5 \\
\hline Hispanic & 22.0 & 14.0 & $a$ & $a$ & 21.5 & 7.4 \\
\hline Mexican American & $a$ & $a$ & 59.7 & 37.1 & $a$ & $a$ \\
\hline Other Hispanic & a & a & 48.5 & $a$ & $\mathrm{a}$ & a \\
\hline
\end{tabular}

Abbreviations: CDC, Centers for Disease Control and Prevention; COVID-19, coronavirus disease 2019; CoVID-NET, COVID-19-Associated Hospitalization Surveillance Network; NCHS, National Center for Health Statistics; NHANES, National Health and Nutrition Examination Survey; NHIS, National Health Interview Survey.

${ }^{a}$ Studies vary in definitions used for Hispanic ethnicity. 
Table 2. Implications of COVID-19 for Oral Health in the United States, 2020

\begin{tabular}{|c|c|c|}
\hline $\begin{array}{l}\text { Core Functions of } \\
\text { Public Health }\end{array}$ & Public Health Concerns & Future Opportunities \\
\hline \multirow{3}{*}{ Assurance } & $\begin{array}{l}\text { Limited access to dental care compounded by COVID-19; aerosol- } \\
\text { generating dental procedures increase risk of transmission }\end{array}$ & $\begin{array}{l}\text { Promote prevention and use of nonaerosol-generating dental } \\
\text { procedures; advance teledentistry training and reimbursement } \\
\text { and other efforts to reach patients outside of the dental setting }\end{array}$ \\
\hline & $\begin{array}{l}\text { Regulations in some states limit dental hygienists' and other dental } \\
\text { team members' ability to provide care in settings outside of the dental } \\
\text { office }\end{array}$ & $\begin{array}{l}\text { Modify state dental practice acts and other regulations for dental } \\
\text { workforce reform and to increase access to prevention }\end{array}$ \\
\hline & $\begin{array}{l}\text { Lack of integration between oral health and the rest of the health care } \\
\text { system }\end{array}$ & $\begin{array}{l}\text { Increase integration between oral health care and primary care (ie, } \\
\text { locations serving patients who are pregnant, have diabetes or } \\
\text { cardiovascular disease) }\end{array}$ \\
\hline \multirow{3}{*}{ Assessment } & $\begin{array}{l}\text { Lack of timely national oral health data and coordinated state and local } \\
\text { information }\end{array}$ & $\begin{array}{l}\text { Monitor oral health conditions as a result of delayed dental care } \\
\text { during pandemic; include oral health metrics in health care quality } \\
\text { measures }\end{array}$ \\
\hline & $\begin{array}{l}\text { Lack of information about health and safety of dental health care } \\
\text { personnel during COVID-19; limited availability of PPE and COVID-19 } \\
\text { testing for dental practices }\end{array}$ & $\begin{array}{l}\text { Monitor dental workforce health and safety; increase availability of } \\
\text { PPE and COVID-19 tests for dental care settings }\end{array}$ \\
\hline & $\begin{array}{l}\text { Evidence needed to determine most cost-effective PPE or PPE } \\
\text { combinations and other measures to prevent SARS-CoV- } 2 \text { in dental } \\
\text { settings }\end{array}$ & $\begin{array}{l}\text { Further testing of specific PPE and PPE combinations and other } \\
\text { measures to protect patient and provider health in dental settings }\end{array}$ \\
\hline \multirow{4}{*}{ Policy Development } & $\begin{array}{l}\text { Potential public and provider unease about seeking and providing } \\
\text { dental care during pandemic }\end{array}$ & $\begin{array}{l}\text { Provide clear communication about how to safely obtain and } \\
\text { provide dental care during the pandemic }\end{array}$ \\
\hline & Oral health not prioritized & $\begin{array}{l}\text { Educate about importance of oral health and its relation to the } \\
\text { health of the rest of the body; provide parity with health care } \\
\text { policies (ie, Medicaid, Medicare) }\end{array}$ \\
\hline & Varied state-level adult dental Medicaid benefits & $\begin{array}{l}\text { Advocate for sustained dental Medicaid funding and expansion to } \\
\text { close coverage gaps }\end{array}$ \\
\hline & $\begin{array}{l}\text { Reimbursement models incentivize surgical, high-end restorative dental } \\
\text { procedures }\end{array}$ & $\begin{array}{l}\text { Modify reimbursement to provide incentives for prevention, } \\
\text { maintaining health, teledentistry }\end{array}$ \\
\hline
\end{tabular}

Abbreviations: COVID-19, coronavirus disease 2019; PPE, personal protective equipment; SARS-CoV-2, severe acute respiratory syndrome coronavirus 2.

The opinions expressed by authors contributing to this journal do not necessarily reflect the opinions of the U.S. Department of Health and Human Services, the Public Health Service, the Centers for Disease Control and Prevention, or the authors' affiliated institutions. 